\title{
Survey on the Prevalence, Awareness, Treatment, and Control of Hypertension among Tibetans at High-altitude in China Ngawa
}

\section{Tingxin Li}

Health management center, Sichuan provincial people's hospital

\section{Lifeng Dan}

School of medicine, University of Electronic Science and Technology of China

\section{Jing Guo}

Health Check-ups Department, People's Hospital in Ngawa

\section{Pengcuo Sanlang}

Health Check-ups Department, People's Hospital in Ngawa

\section{Lin Wang}

Health managements center, Sichuan provincial People's Hospital

Jinhong Wang ( $\sim$ jinhong@snnu.edu.cn )

Shaanxi Normal University https://orcid.org/0000-0002-0669-2939

\section{Research article}

Keywords: Hypertension, prevalence, awareness, Tibetan, high-altitude, Ngawa

Posted Date: April 23rd, 2020

DOl: https://doi.org/10.21203/rs.3.rs-22881/v1

License: (1) This work is licensed under a Creative Commons Attribution 4.0 International License. Read Full License 


\section{Abstract \\ Background:}

The prevalence of hypertension in China increased recent years. There are some surveys reported the hypertension status in different regions in China. However, little data revealed the epidemic status of hypertension among Tibetans at high altitude area in Ngawa. In this study, we explored the prevalence, awareness, treatment and control of hypertension in this special population.

\section{Methods:}

The cross-sectional analysis data was collected from 2228 Tibetan residents in seven high-altitude areas of Ngawa from September 2018 to June 2019, using a stage cluster sampling method. All participants were measured their blood pressure by trained physicians and have completed the questionnaire in the local hospital and health clinics. Hypertension was defined as systolic blood pressure (SBP) $\geq$ $140 \mathrm{mmHg}$ and /or diastolic blood pressure(DBP) $\geq 90 \mathrm{mmHg}$ according to standards in China.

\section{Results:}

The prevalence rate of hypertension was $24.6 \%$ in this area, which was similar to previous survey results the general population in China (23.2\%). The awareness rate (32.3\%), treatment rate $(21.7 \%)$, and control rate $(6.2 \%)$ of hypertension in high altitudes were lower than in the plain area in China. Compared to the 2015 Sichuan rural survey, the awareness rate increased (32.3\% vs $24.6 \%)$, but the treatment rate $(21.7 \%$ vs $24.7 \%)$ and the control rate $(6.2 \%$ vs $14.7 \%)$ remained low.

\section{Conclusions:}

From the results, we can come to a conclusion that the rates of awareness, treatment, and control of hypertension remain unexpected low in Tibetans, especially in female Tibetan at high altitude area of Ngawa. The related factors may include poor medical conditions, economic underdevelopment and traditional Tibetan customs. We hope to add some Tibetan data to the clinical epidemiology database of hypertension and hope the study can be used for future research.

\section{Background}

High morbidity and mortality of cardiovascular disease are rapidly becoming the leading cause of death worldwide recent years, and this is the case in China[1, 2]. Hypertension, as a major risk factor for cardiovascular disease, has affected $26.4 \%$ of the world's adult population (972 million) in 2000 , and the ratio is expected to increase to $29.2 \%$ (1.56 billion) by $2025[3,4,5]$. In China, the ratio is $23.2 \%$

(0.245 billion) according to the Nutrition and Health Survey in 2018[6]. 
Hypertension is a serious threat to Chinese. The average rate of the prevalence, awareness, treatment and control of hypertension is $37.2 \%, 36.0 \%, 22.9 \%$, and $5.7 \%$ respectively in China [9-11]. Two studies further analyzed the relation between the prevalence of hypertension and the altitude. However, it was all in the general population, and the status of blood pressure of the Tibetans in Ngawa is rarely reported, especially in remote and underdeveloped high altitudes.

Ngawa Tibetan Autonomous Prefecture, located in the high altitude area of Sichuan Provence, has unique geographic characteristics and different habits from other parts of China. The main residents in Ngawa are Ando Tibetan and White-horse Tibetan, who belong to different branches of the Tibetan. Having lived with the Han people for decades, their lifestyle and health may differ from traditional Tibetans. People here tend to eat a high-salt, fat-rich diet and lack vegetables. Unhealthy lifestyle may increase the risk of hypertension when medical resource is inadequate. In addition, in recent years, few reports have focused on the epidemiological features of cardiovascular disease in this region. Therefore, it is especially critical to access more epidemiological data on risk factors for cardiovascular disease to improve medical standards and health in this area. To achieve this goal, we explore the prevalence, awareness, treatment, and control of hypertension in this special population at high altitudes in the study.

\section{Methods}

\section{Sampling Method and Subject Selection}

Ngawa Tibetan Autonomous Prefecture is located in northwest of Chinese Sichuan province and consists of Maerkang city and 12 counties, where more than 536000 Tibetans live[12]. In our study, about $0.5 \%$ of all Tibetans from seven high-altitude areas (Maerkang City, Rangtang County, Jinchuan County, Aba County, Hongyuan County, Xiaojin County and Maoxian County) were selected as our study subjects by random sampling method (Fig. 1,2). In this survey, we excluded pregnant women, and patients with malignant tumors, mental health problems, and with severe cardiovascular disease such as coronary heart disease, stroke, macroangiopathy. Patients who were reluctant to complete all the required questions were also excluded from the survey. All subjects had signed an informed consent form after understanding the objectives and benefits of our study. This study was approved by the Ethics Committee of Sichuan Provincial People's Hospital (Chengdu, China).

\section{Data Collection}

Questionnaires were conducted by trained investigators during face-to-face interviews with subjects, whose blood pressure was measured by doctors in local hospitals and health clinics. The survey questionnaires included: (1) Demographic characteristics including age, gender, education, and location of residency; (2) Medical, personal, and family health history, involving a family history of hypertension, current and past use of medications. Family history of hypertension was defined as an immediate family member of a subject who was previously diagnosed with hypertension, such as a parent, child, brother, or 
sister; (3) Health care access and behaviors, including medical check-ups in the past 2 years. The proportion for each choice was calculated by dividing the number of selected subjects by the total number of subjects.

\section{Blood Pressure Measurement}

Doctors performed BP measurements following American National Management of Essential Hypertension and Chinese Hypertension Guidelines $[13,14]$. Each subject was measured with BP after a five-minute break, given two readings in a mercuric-column sphygmomanometer, and then averaged two measurements.

\section{Definitions}

Subjects were judged to have hypertension by an average SBP $\geq 140 \mathrm{~mm} \mathrm{Hg}$, and/or average DBP $\geq$ $90 \mathrm{~mm} \mathrm{Hg}$, and/or who had previously been diagnosed with hypertension or were currently taking antihypertensive medicines. Awareness of hypertension was defined as claiming to have ever been diagnosed with hypertension by doctors and /or knowing that they were taking antihypertensive drugs. Treatment of hypertension was judged by responding "yes" when asked if he was taking antihypertensive medicines. Control of hypertension was defined as over twice reading an average SBP $<140 \mathrm{~mm} \mathrm{Hg}$ and an average $\mathrm{DBP}<90 \mathrm{~mm} \mathrm{Hg}$. Weight and height measurement errors were respectively $0.2 \mathrm{Kg}$ and $1 \mathrm{~cm}$. Body mass index (BMI) was defined as weight $(\mathrm{Kg})$ divided by squared height $\left(\mathrm{m}^{2}\right)$. According to the Chinese Guidelines for Prevention and Control of Adult Overweight and Obesity[15],overweight is defined as a BMI between $24 \mathrm{Kg} / \mathrm{m}^{2}$ and $28 \mathrm{Kg} / \mathrm{m}^{2}$; and obesity is defined as a BMI great than or equal to 28 $\mathrm{Kg} / \mathrm{m}^{2}$. Routine medical examination was defined as a regular check-up at least once every two years in public hospitals or clinics. The level of education was assessed as elementary school or lower, middle school, or high school or above.

\section{Statistical Analyses}

Baseline features were described as a mean $(S D)$ for continuous variables and the number (proportion) for categorical variables. The categorical variables were compared by the $\chi 2$ test. The linear trend across $\mathrm{BMI}$ groups was tested by the Mantel-Haenszel $\chi 2$ statistic. Multivariate logistic regression models were used to explore the correlation between baseline features and prevalence, awareness, and control rate, which were calculated using odds $(O R s)$ and corresponding $95 \%$ confidence intervals $(95 \% \mathrm{Cls})$. $P$ values less than 0.05 were considered statistically significant. All analyses were performed with SPSS 17.0.

\section{Results}

\section{Demographic Characteristics}


The results showed that the subjects were between 18 and 80 years old, with an average age of $45.00 \pm$ 14.01. Male subjects were $1310(58.8 \%)$, while female were $918(41.2 \%)$. About $40 \%$ of subjects have a secondary school or lower education, and $63 \%$ of subjects (1404) were able to have a physical examination at least every 2 years (Table 1 ).

Table 1

Characteristics of Study Subjects, by Gender

\begin{tabular}{|c|c|c|c|}
\hline Variable & Male(n = 1310),n(\%) & Female(n = 918),n(\%) & Total(n = 2228),n(\%) \\
\hline Age(yrs) & $47.15 \pm 14.29$ & $41.93 \pm 13.02$ & $45.00 \pm 14.01$ \\
\hline $\mathrm{BMI}\left(\mathrm{Kg} / \mathrm{m}^{2}\right)$ & $24.45 \pm 2.53$ & $22.25 \pm 2.81$ & $23.55 \pm 2.86$ \\
\hline \multicolumn{4}{|l|}{ Education level } \\
\hline Elementary school or lower & $506(42.6)$ & $325(36.5)$ & $831(40.0)$ \\
\hline Middle school & $214(18.0)$ & $141(15.8)$ & $355(17.1)$ \\
\hline High school or above & $467(39.3)$ & $424(47.6)$ & $891(42.9)$ \\
\hline \multicolumn{4}{|l|}{ Altitude(m) } \\
\hline $1500 \sim 2500$ & $346(26.4)$ & $142(15.5)$ & $488(21.9)$ \\
\hline $2500 \sim 3500$ & $772(58.9)$ & $596(64.9)$ & $1368(61.4)$ \\
\hline$\geq 3500$ & 192(14.7) & 192(14.7) & $372(16.7)$ \\
\hline \multicolumn{4}{|l|}{ Region } \\
\hline City & $624(47.6)$ & $484(52.7)$ & 1108(49.7) \\
\hline County & $686(52.4)$ & $434(47.3)$ & $1120(50.3)$ \\
\hline \multicolumn{4}{|l|}{ Regular check-up } \\
\hline Yes & $802(61.2)$ & $602(65.6)$ & $1404(63.0)$ \\
\hline No & $508(38.8)$ & $316(34.4)$ & $824(37.0)$ \\
\hline
\end{tabular}

\section{Prevalence, Awareness, Treatment, And Control Of Hypertension}

Based on the measurement values taken at the interview, the mean SBP and DBP were $128.23 \pm 14.06$ and $79.08 \pm 10.89 \mathrm{~mm} \mathrm{Hg}$. The result showed that the prevalence rate was $24.6 \%$ (548/2228); the awareness rate was $32.3 \%(177 / 548)$;the treatment rate was $21.7 \%(119 / 548)$; and the control rate was 
only $6.2 \%(34 / 548)$. Only $16 \%$ of subjects (304) understand hypertension diagnosis standards correctly. About $53.3 \%$ of the subjects (1188) were not very clear about the criteria for diagnosis of hypertension.

\section{Hypertension Status And Demographic Characteristics}

The prevalence of hypertension in male was significantly higher than in female (30.0\% vs $16.9 \%)$, but there is no statistical difference between the control rate and the gender (6.6\% vs $5.2 \%$ ) (Table 2 ). The prevalence of the under - 40 age group was significantly lower than in the 40-59 age groups, especially in the over-60 age group $(5.9 \%$ vs $29.6 \%, 5.9 \%$ vs $52.9 \%, P<0.0001)$. The awareness and treatment were higher in the 40-59 age group than in the group under 40 and the group over $60(P<0.0001)$, but the control rate was still low in these three different age groups (Fig. 3). 
Table 2

Relationship between hypertension status and demographic characteristics

\begin{tabular}{|c|c|c|c|c|c|c|}
\hline Characteristics & & $\mathbf{n}$ & $\begin{array}{l}\text { Prevalence, } \\
\mathrm{n}(\%)\end{array}$ & $\begin{array}{l}\text { Awareness, } \\
\mathrm{n}(\%)\end{array}$ & $\begin{array}{l}\text { Treatment, } \\
\mathrm{n}(\%)\end{array}$ & $\begin{array}{l}\text { Control, } \\
\mathrm{n}(\%)\end{array}$ \\
\hline Gender & $P$ & & $<0.0001^{*}$ & $0.002^{\star}$ & $0.026 *$ & 0.525 \\
\hline Male & & 1310 & 393(30.0) & $142(36.1)$ & $95(24.2)$ & $26(6.6)$ \\
\hline Female & & 918 & $155(16.9)$ & $35(22.6)$ & $24(15.5)$ & $8(5.2)$ \\
\hline Age(yrs) & $P$ & & $<0.0001^{*}$ & $<0.0001 *$ & $<0.0001^{*}$ & 0.176 \\
\hline $18-39$ & & 876 & $52(5.9)$ & $5(9.6)$ & $2(3.8)$ & 1(1.9) \\
\hline $40-59$ & & 942 & $279(29.6)$ & $116(41.6)$ & $78(28.0)$ & $22(7.9)$ \\
\hline $60-80$ & & 410 & $217(52.9)$ & $56(25.8)$ & $39(18.0)$ & $11(5.1)$ \\
\hline Education level & $P$ & & $<0.0001^{\star}$ & $<0.0001^{\star}$ & 0.051 & $0.018^{*}$ \\
\hline $\begin{array}{l}\text { Elementary school or } \\
\text { lower }\end{array}$ & & 831 & $325(39.1)$ & $79(24.3)$ & $57(17.5)$ & $12(3.7)$ \\
\hline Middle school & & 355 & $65(18.3)$ & $25(38.5)$ & $19(29.2)$ & $6(9.2)$ \\
\hline High school or above & & 891 & 118(13.2) & $50(42.4)$ & $29(24.6)$ & $12(10.2)$ \\
\hline Family history & $P$ & & $<0.0001^{*}$ & $<0.0001^{*}$ & $<0.0001^{*}$ & 0.177 \\
\hline Yes & & 182 & $98(53.8)$ & $62(63.5)$ & $55(43.9)$ & $9(9.2)$ \\
\hline No & & 2046 & $450(22.0)$ & $115(25.6)$ & $76(16.9)$ & $25(5.6)$ \\
\hline Altitude(m) & $P$ & & $<0.0001^{*}$ & $<0.0001^{\star}$ & 0.246 & $0.039 *$ \\
\hline $1500 \sim 2500$ & & 488 & 168(34.4) & $72(42.9)$ & $40(23.8)$ & $16(9.5)$ \\
\hline $2500 \sim 3500$ & & 1368 & $252(18.4)$ & $82(32.5)$ & $58(23.0)$ & $15(6.0)$ \\
\hline$\geq 3500$ & & 372 & $128(34.4)$ & $23(18.0)$ & 21(16.4) & $3(2.3)$ \\
\hline Region & $P$ & & $<0.0001^{*}$ & $0.026^{\star}$ & $0.007 *$ & 0.294 \\
\hline City & & 1108 & 196(17.7) & $75(38.3)$ & $55(28.1)$ & $15(7.7)$ \\
\hline County & & 1120 & $352(31.4)$ & 102(29.0) & $64(18.2)$ & $19(5.4)$ \\
\hline $\mathrm{BMI}\left(\mathrm{Kg} / \mathrm{m}^{2}\right)$ & $P$ & & $<0.0001^{*}$ & $<0.0001^{\star}$ & 0.121 & 0.221 \\
\hline$<24$ & & 1292 & 218(16.9) & $66(30.3)$ & $57(26.1)$ & $17(7.8)$ \\
\hline 24-28(overweight) & & 794 & $259(32.6)$ & $69(26.6)$ & $48(18.5)$ & $13(5.0)$ \\
\hline$\geq 28$ (obesity) & & 136 & $71(52.2)$ & $42(59.2)$ & $14(19.7)$ & $2(2.8)$ \\
\hline
\end{tabular}




\begin{tabular}{|c|c|c|c|c|c|}
\hline Characteristics & $\mathrm{n}$ & $\begin{array}{l}\text { Prevalence, } \\
\mathrm{n}(\%)\end{array}$ & $\begin{array}{l}\text { Awareness, } \\
\mathrm{n}(\%)\end{array}$ & $\begin{array}{l}\text { Treatment, } \\
\mathrm{n}(\%)\end{array}$ & $\begin{array}{l}\text { Control, } \\
\text { n(\%) }\end{array}$ \\
\hline Regular check-up & $P$ & $<0.0001 *$ & $0.003^{\star}$ & $<0.0001^{\star}$ & 0.692 \\
\hline Yes & 1404 & 268(19.9) & 99(38.7) & $73(28.5)$ & $17(6.6)$ \\
\hline No & 824 & 280(34.0) & $78(26.7)$ & $46(15.8)$ & $17(5.8)$ \\
\hline Total & 2228 & $548(24.6)$ & 177(32.3) & 119(21.7) & $34(6.2)$ \\
\hline
\end{tabular}

In the higher education-level group, the prevalence is lower, the awareness rate and the treatment rate are higher, while in the lower education group, the opposite is true. Interestingly, the group of subjects with a family history of hypertension had higher prevalence, awareness and treatment rates than those without $(P<0.0001)$.Further analysis found that subjects with higher BMI were associated with higher hypertension prevalence and awareness $(P<0.0001)$. The region analysis found that the three rates of urban residents were lower than that of county residents $(P<0.05)$. Another finding was that people who had regular check-ups had a lower prevalence and higher awareness and treatment than those who rarely had it $(P<0.01)$. Altitude analysis showed significant difference in prevalence, awareness and control rates in individual high-altitude subgroups $(P<0.001, P<0.001, P=0.039)$. Unfortunately, the treatment and control rates of all subgroups in our study were lower than the Chinese average.

\section{Multivariate Analyses About Prevalence, Awareness, And Treatment Of Hypertension}

Female, age (under 60), altitude of 2500-3500 meters and high education level were significantly associated with higher prevalence of hypertension, while family history of hypertension, overweight and obesity were significantly associated with lower prevalence( $(\mathrm{P}<0.001$, Fig. 4). Male, urban and plain areas, regular check-ups, family history of hypertension, high education, overweight and obesity were all obviously associated with higher awareness of hypertension $(P<0.05$, Fig. 5$)$. Age under 60 , urban and family history of hypertension were associated with higher treatment of hypertension $(P<0.05$, Fig. 6$)$.

\section{Discussion}

This survey covered about $0.5 \%$ all Tibetans from seven different high-altitudes in Ngawa and the results were representative. It showed the prevalence rate of hypertension was $24.6 \%$, which was similar to previous survey results in Tibet (23-56\%)[16-18], in Sichuan province(25.2\%)[19], and in nationally $(23.2 \%)[6,21,22]$.

In our study, the awareness, treatment and control rate were $32.3 \%, 21.7 \%$ and $6.2 \%$ respectively, which were lower than in Guo's report $(36.1 \%, 12.4 \%$, and 30.5\% )[23]. Compared with the 2015 Sichuan rural 
survey, the awareness rate of hypertension in Tibetan has increased (32.3\% vs 24.6\%), but the treatment rate $(21.7 \%$ vs $24.7 \%)$ and the control rate $(6.2 \%$ vs $14.7 \%)$ need to be further improved[19].

Multivariate attributive analysis showed residents at high altitude had high risk of hypertension. Perhaps main reason is their special lifestyle in this area. Firstly, at high altitudes, food resources are limited and food diversity is insufficient. Secondly, people in Ngawa like to eat traditional salty yak butter milk tea, highland barley wine and Yak meat, which are specialties of the plateau area [25]. Finally, air-dried bacon is a common way to entertain guests in the area due to the alpine climate and traditional customs. People have unique diet that prioritizes meat, alcohol, and salt-rich food, which all increase the risk of hypertension.

We speculated that the low rate of awareness and treatment was due to their difficulty in obtaining medical examinations and health care knowledge at high altitudes. Although the level of government's health care in the region had improved in recent years, access to medical resources for the inhabitants of the Plateau is still insufficient. Hypertension remains a major public health problem in this special population. More methods and information communication technology could improve blood pressure control in Ngawa[26, 27].

There are significant differences in hypertension awareness and treatment rates in different age groups. The prevalence of hypertension in people over 60 years of age group was as high as $52.9 \%$ (Table 2). But the awareness and treatment rates was only $25.8 \%$ and $18 \%$ in this group. About $89 \%$ patients did not effectively control their blood pressure. Elderly patients may pay less attention to their health due to their lower education level and less medical knowledge, which leads to lower awareness and treatment rates. Another noteworthy is that nearly one-third of subjects in the 40-59 age groups had hypertension, and they were more likely to be taking anti-hypertensive medications than the older and younger groups, but the control rate $(7.9 \%)$ was not satisfied. They are the backbone of society and the family, busy with work, neglecting to pay attention to their own health, which was also the reason for the lower awareness and treatment rate. Therefore, the level of health care in these areas needs to be further improved. But these patients would be benefited from appropriate therapy at most, and if treated, would have more control over their blood pressure [22].

It was disagreed with the results from other studies $[28,29]$, this study showed that female hypertension patients had lower effective awareness and treatment rate of BP than their male counterparts. We hypothesized that women in this group had low social status owing to their traditional customs. As a loyal housewife, women might not paying enough attention to their health, which may cause to low awareness and treatment rates in women patients. Further research is needed to confirm this hypothesis.

Although subjects with a family history of hypertension had 3.86-fold higher risk of developing hypertension (Fig. 4), fortunately, their awareness and treatment rate were higher. Maybe the high prevalence of the disease in their families helps them to better understand hypertension and prompts them to be more proactive in treating it. This trend was also mentioned in the Lebanon population in 2018[29]. 
In our study, obesity and overweight were associated with high prevalence of hypertension and subsequent awareness. Unfortunately, a larger proportion of patients remain uncontrolled. Other studies have received the same results as well[10,20]. In our study, although subjects with a bachelor's degree or higher education had higher awareness rate, they did poor job of treating and controlling their blood pressure. This was also mentioned in the Jackson Heart Study [30]. The lower awareness rate was associated with lower education level and lower treatment rate was related to lack of medical care at high-altitudes. Low adherence may also reduce the control rate. Early detection and regular treatment guidelines were necessary to reduce low adherence in this area.

This study has some limitations. First, it was a cross sectional study, so it is limited in determining the direction of the association, as the exposure and the outcome are simultaneously assessed. Prospective studies are required for further investigation of these findings. Second, some of the selected residents, especially Tibetans over 70 years of age, were reluctant to go to the clinic for a check-up and fill out the questionnaire, which might lead to selection bias and cover up the actual survey data. Further epidemiological studies are needed to obtain more comprehensive information and data in order to develop appropriate prevention strategies and controls.

\section{Conclusions}

This study first time surveyed the hypertension epidemiology in Tibetans population in high altitude area Ngawa. The From the results, we can come to a conclusion that the treatment and the control rate of hypertension is not optimistic in Tibetan, especially in female Tibetan in Ngawa area due to lack of medical condition, undeveloped economy or Tibetan's traditional customs. We hope to add some Tibetan data to the clinical epidemiology database of hypertension and hope the study can be used for future research.

\section{Abbreviations}

BMI

body mass index

SBP

Systolic blood pressure;

DBP

Diastolic blood pressure;

HBP

High blood pressure;

OR

Odds ratios;

$\mathrm{Cl}$

Confidence intervals;

SPSS

Page $10 / 18$ 


\section{Declarations}

\section{Availability of data and materials}

The data-set used and/or analyzed during the current study is available from the corresponding author on reasonable request.

\section{Ethics approval and consent to participate}

The Medical Ethics Committee of Sichuan Provincial People's Hospital approved the survey in accordance with the guidelines of the Declaration of Helsinki. Verbal informed consent was obtained from all survey participants.

\section{Consent for publication}

Not applicable.

\section{Publisher's Note}

Springer Nature remains neutral with regard to jurisdictional claims in published maps and institutional affiliations

\section{Competing interests}

The authors declare that they have no competing interests.

\section{Funding:}

This study was supported by Health Department of Sichuan Province (Grant No. 18PJ585 and No. 2018 228). The funding was mainly used in study design; in the clinical check-ups for participators; in the collection, analysis and interpretation of data; in the submission of the article for publication.

\section{Contributions}

Tingxin Li and Lifeng Dan contributed equally to this work. Tingxin Li designed the study, participated in the statistical analysis and reviewed the manuscript. Lifeng Dan participated in the study design and 
helped to draft the manuscript. Jinhong Wang and Lin Wang have been involved in drafting the manuscript and revising it critically for important intellectual content. All authors read and approved the final version of the manuscript.

\section{Acknowledgments:}

We are grateful to all study participants for their active cooperation. We acknowledge contribution of our survey team members, interviewers, leaders and volunteers for their continuous efforts in the field survey.

\section{References}

1. GBD 2013 Mortality and Causes of Death Collaborators. Global, regional,and national age-sex specific all-cause and cause-specific mortality for 240 causes of death, 1990-2013: a systematic analysis for the global burden of disease study 2013. Lancet. 2015;385:117-71.

2. GBD Causes of Death Collaborators. Global, regional, and national age-sex specific mortality for 264 causes of death, 1980-2016: a systematic analysis for the global burden of disease study 2016. Lancet. 2017;390:1151-210.

3. Chow CK, Teo KK, Rangarajan S, et al. PURE (Prospective Urban Rural Epidemiology) Study investigators. Prevalence, awareness, treatment, and control of hypertension in rural and urban communities in high-, middle-, and low-income countries. JAMA. 2013;310:959-68.

4. GBD Mortality Collaborators. Global, regional, and national under-5 mortality, adult mortality, agespecific mortality, and life expectancy, 1970-2016: a systematic analysis for the global burden of disease study 2016. Lancet. 2017;390:1084-150.

5. Kearney PM, Whelton M, Reynolds K, et al. Global burden of hypertension: analysis of worldwide data. Lancet. 2005;365:217-23.

6. Wang Z, Chen Z, Zhang L, et al. Status of Hypertension in China: Results From the China Hypertension Survey, 2012-2015. Circulation. 2018;29(22):2344-56. 137(.

7. Mingji C, Onakpoya IJ, Perera R, et al. Relationship between altitude and the prevalence of hypertension in Tibet: a systematic review[J]. Heart. 2015;101(13):1054-60.

8. Yue L, Fan Z, Sun L, et al. Prevalence of Essential Hypertension and Its Complications Among Chinese Population at High Altitude. High Alt Med Biol. 2017;18(2):140-4.

9. Hou Z, Meng Q, Zhang Y, Hypertension Prevalence. Awareness, Treatment, and Control Following China's Health care Reform. Am J Hypertens. 2016;29:428-31.

10. Wang J, Zhang L, Wang F, et al China National Survey of Chronic Kidney Disease Working Group. Prevalence, awareness, treatment, and control of hypertension in China: results from a national survey. Am J Hypertens. 2014;27:1355-61.

11. Li J, Shi L, Li S, et al. Urban-rural disparities in hypertension prevalence, detection, and medication use among Chinese adults from 1993 to 2011. Int J Equity Health. 2017;16:50. 
12. Ngawa Tibetan. and Qiang autonomous prefecture people's government: Ngawa state national economic and social development statistics Bulletin in 2018, 2019-04-28.

13. Ferdinand KC, Nasser SA. Management of Essential Hypertension. Cardiol Clin. 2017;35(2):231-46.

14. Wang J-G,Chinese Hypertension Guidelines. Pulse (Basel). 2015; 3(1): 14-20.

15. Chen CM, Kong LZ. Chinese guidelines for Prevention and Control of Adult Overweight and Obesity. Beijing: People's Medical Publishing House; 2006.

16. Zhao X, Li S, Ba S, et al. Prevalence, awareness, treatment, and control of hypertension among herdsmen living at 4,300 m in Tibet. Am J Hypertens. 2012;25:583-9.

17. Sherpa LY, Deji, Stigum H, et al. Prevalence of metabolic syndrome and common metabolic components in high altitude farmers and herdsmen at $3700 \mathrm{~m}$ in Tibet. High Alt Med Biol. 2013;14:37-44.

18. Zhang HT, Zhou YL, Gao L, et al. An epidemiological study on the hypertension and cerebral stroke in Ganzi Tibetan state. Chin J Evid Based Med. 2012;12:173-5.

19. Wu X, Li L, Chen X, Luo G, et al. Characteristics of hypertension prevalence and related factors in rural area in Sichuan. Zhonghua Liu Xing Bing Xue Za Zhi. 2015;36(11):1216-9.

20. Dickson BK, Blackledge J, Hajjar IM. The impact of lifestyle behavior on hypertension awareness, treatment, and control in a southeastern population. Am J Med Sci. 2006;332(4):211-5.

21. Li Y, Yang L, Wang L, et al. Burden of hypertension in China: A nationally representative survey of 174,621 adults. Int J Cardiol. 2017;227:516-23.

22. Gao Y, Chen G, Tian H, et al. Prevalence of hypertension in china: a cross-sectional study. PLoS One. 2013;8:e65938.

23. Guo J, Yu C, Lyu J, Guo Y, et al. Status of prevalence, awareness, treatment and controll on hypertension among adults in 10 regions, China. Zhonghua Liu Xing Bing Xue Za Zhi. 2016;37(4):469-74.

24. Lu J, Lu Y, Wang X, et al. Prevalence, awareness, treatment, and control of hypertension in China: data from 1.7 million adults in a population-based screening study (China PEACE Million Persons Project). Lancet. 2017;390(10112):2549-58.

25. Xin Z, Qingtao M, Jiayue F,et al. The prevalence of hyperuricemia and its correlates in Ganzi Tibetan Autonomous Prefecture, Sichuan Province, China. Lipids in Health Disease. 2018;17:235.

26. Milani RV, Lavie CJ, Wilt JK,et al. Ventura HO. New concepts in hypertension management: a population-based perspective. ProgCardiovasc Dis. 2016;59:289-94.

27. Kario K. Evidence and perspectives on the 24-hour management of hypertension: hemodynamic biomarker-initiated "anticipation medicine" for zero cardiovascular event. Prog Cardiovasc Dis. 2016;59:262-81.

28. Zhao XL, Chen J, Cui YL, et al. Current status of primary hypertension in China: an epidemiological study of 12 provinces, 1 autonomous region, and 1 municipality. Chin J Med. 2006;86:1148-52. 
29. Noubani A, Nasreddine L, Sibai AM, Prevalence, Awareness, and Control of Hypertension in Greater Beirut Area, Lebanon. Int J Hypertens. 2018; 2018:5419861.

30. Basu S, Millett C. Social epidemiology of hypertension in middle-income countries: Determinants of prevalence, diagnosis, treatment, and control in the WHO SAGE study. Hypertension. 2013;62:18-26.

\section{Figures}

\section{Hongyuan}

County: 372

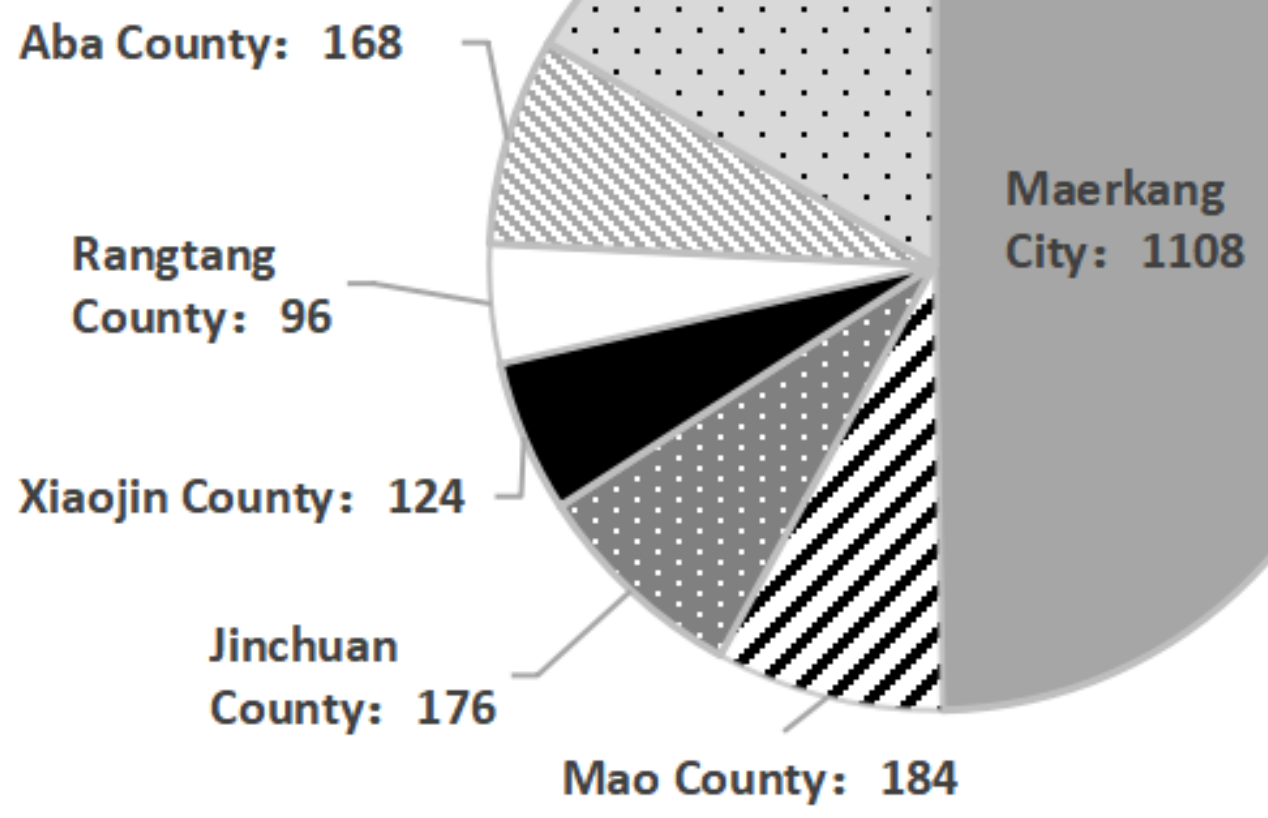

\section{Figure 1}

The regional distribution of samples ( $\mathrm{n}$ ) 


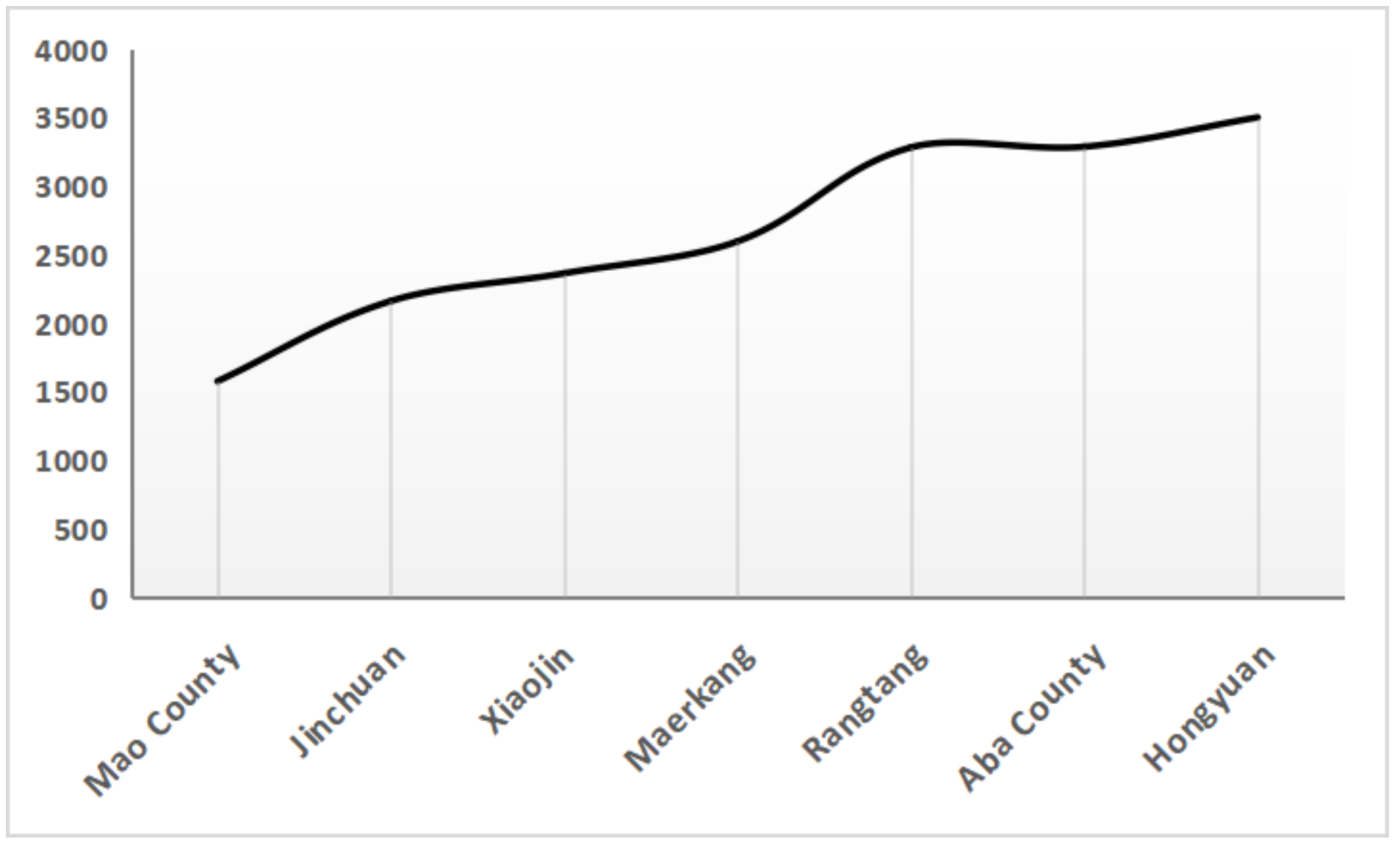

Figure 2

The regional distribution of altitude $(\mathrm{m})$ 

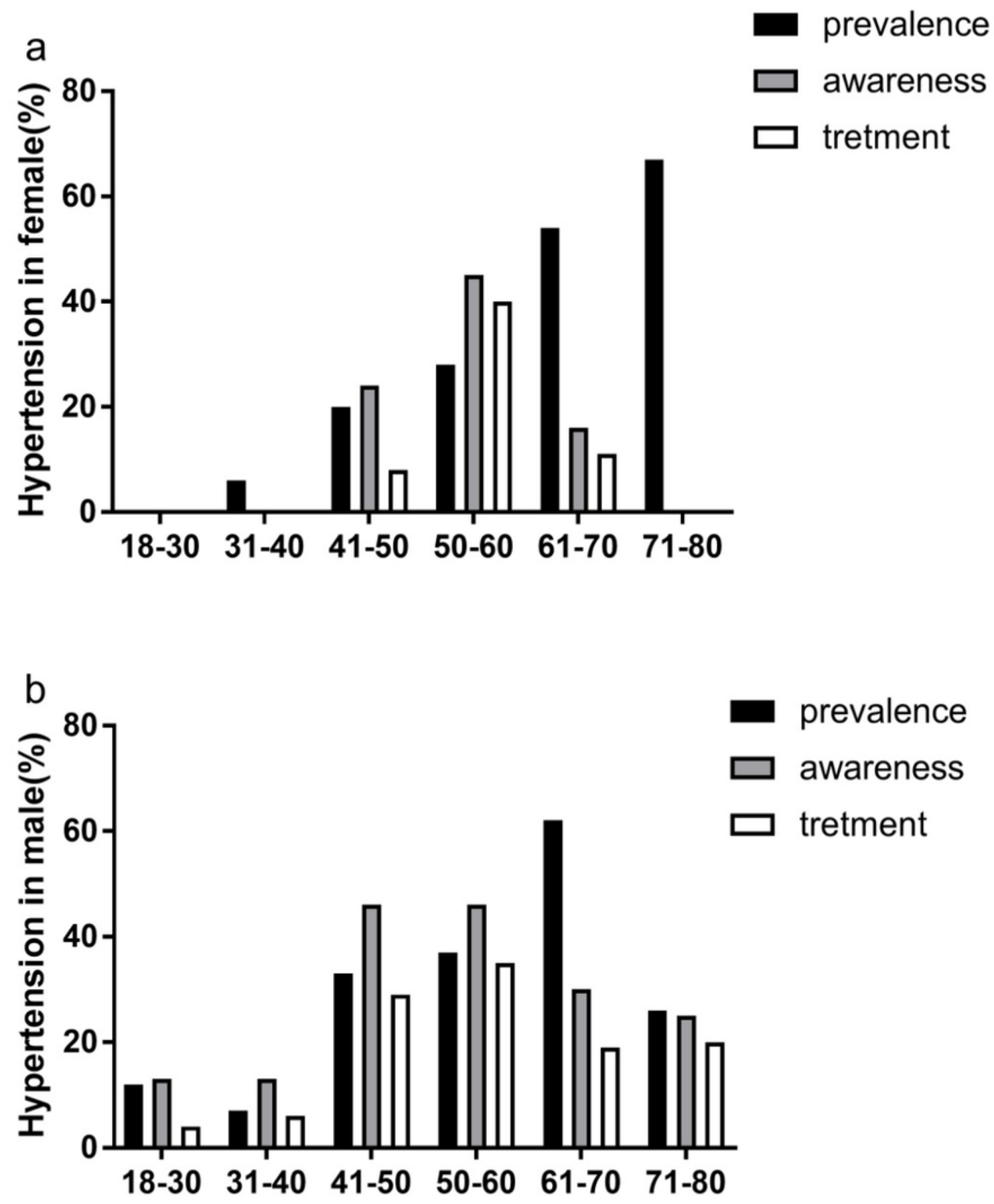

Figure 3 Prevalence, awareness and treatment rate of hypertension by age and sex. a: Female; b: Male

Figure 3

The prevalence/awareness/treatment rate of hypertension in different genders and age groups. 


\begin{tabular}{|c|c|c|c|c|}
\hline Characteristics & & $O R$ & $95 \% C l$ & $P$ value \\
\hline Altitude $\geq 3500 \mathrm{~m}$ r & & 1.49 & $-1.00 \sim 8.71$ & 0.051 \\
\hline Altitude $2500 \sim 3500 \mathrm{~m}$ & $1+1$ & 0.47 & $0.29 \sim 0.74$ & $0.001^{\star}$ \\
\hline Altitude $1500 \sim 2500 \mathrm{~m}$ & & 0 & - & - \\
\hline Elementary school or lower & $\longmapsto$ & 2.03 & $1.42 \sim 2.91$ & $<0.001$ \\
\hline Middle school & - & 1.88 & $1.29 \sim 2.74$ & $0.001^{\star}$ \\
\hline High school or above & & 0 & - & - \\
\hline Obesity & & 5.52 & $3.49 \sim 8.71$ & $<0.001^{\star}$ \\
\hline Overweight & $\mapsto-1$ & 2.53 & $1.96 \sim 3.26$ & $<0.001^{\star}$ \\
\hline Regular check-up & rer & 1.05 & $0.79 \sim 1.39$ & 0.74 \\
\hline Residence in city & $H=-1$ & 1.07 & $0.72 \sim 1.57$ & 0.75 \\
\hline Family history & & 3.86 & $2.58 \sim 5.79$ & $<0.001^{\star}$ \\
\hline Male & HeH & 1.39 & $1.09 \sim 1.78$ & $0.009^{\star}$ \\
\hline Age $<60 y$ & & 0.18 & $0.13 \sim 0.25$ & $<0.001 *$ \\
\hline
\end{tabular}

*: $\quad P<0.05$ was considered statistically significant.

Figure 4

The prevalence Odds Ratio and 95\% Cl from Multiple Logistic Regression

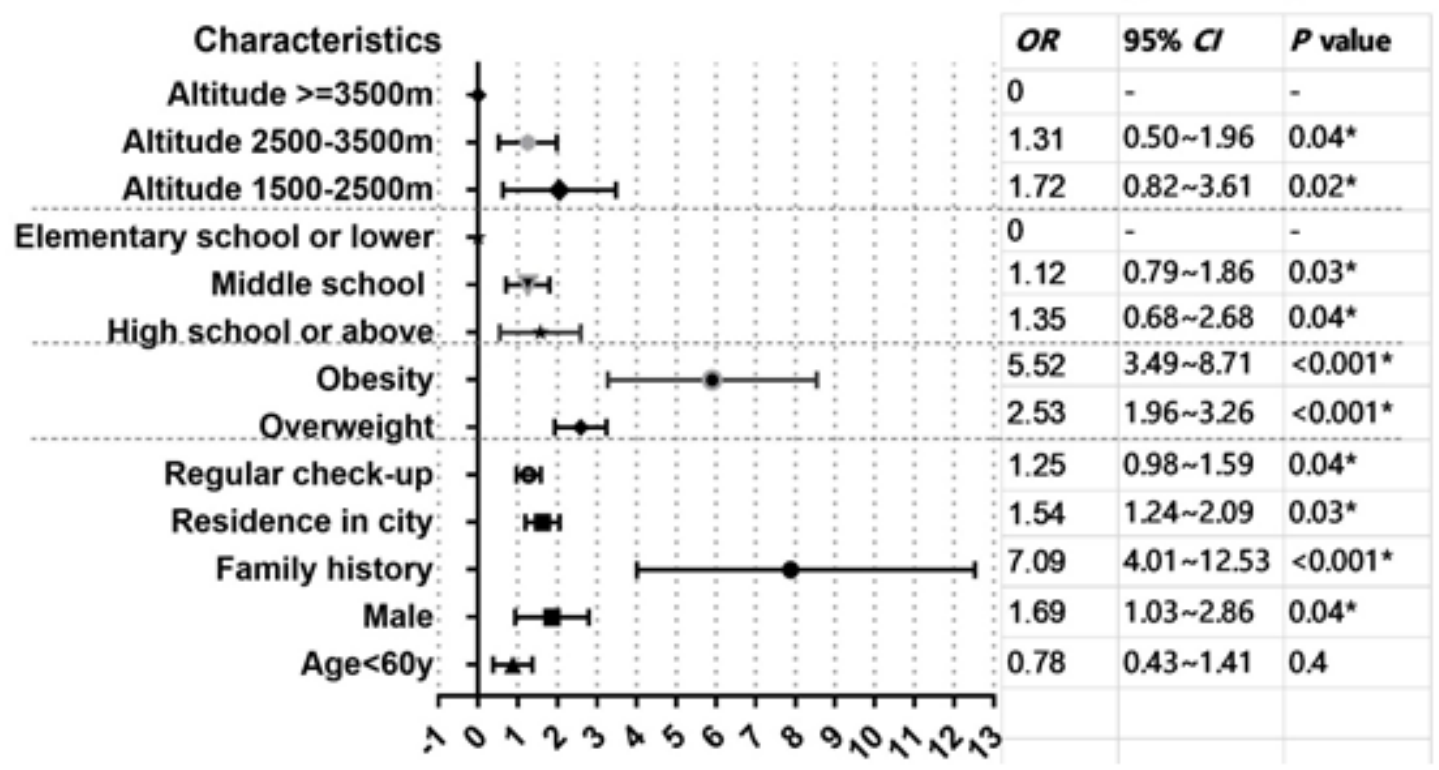

*: $\quad P<0.05$ was considered statistically significant

Figure 5

The Awareness Odds Ratio and 95\% Cl from Multiple Logistic Regression 


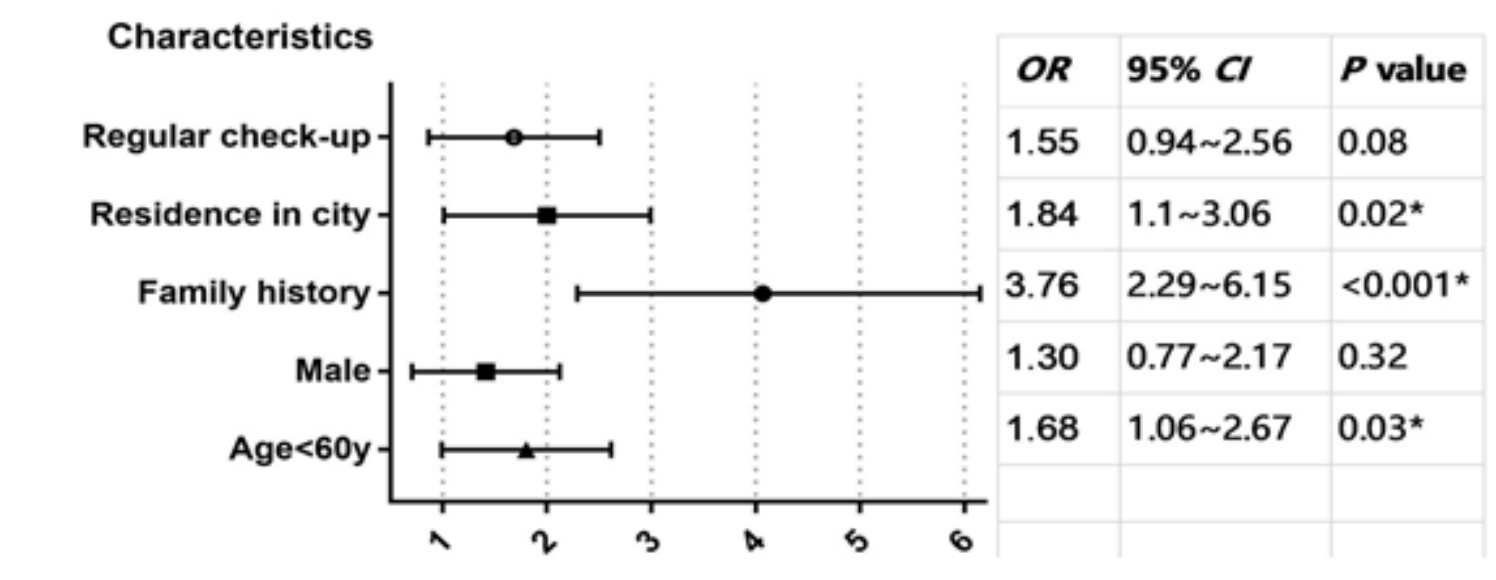

*: $\quad P<0.05$ was considered statistically significant.

\section{Figure 6}

The Treatment Odds Ratio and 95\% Cl from Multiple Logistic Regression 